\title{
A Unique Pedagogical Approach to Voting and Public Goods
}

Douglas A. Schuler, Rice University

Matthew Chappell, University of Idaho, College of Law

L. Scott Baggett, U.S. Department of Agriculture

ABSTRACT Fourth grade students at a public elementary school in Houston, Texas, participated in a one-week exercise intended to mimic the process of creating a public good through a democratic process. The exercise involved students in four separate classes designing a class party with different characteristics (theme, music, and food) through a voluntary but personally costly voting procedure. The students then held the party that they had created. A formal assessment of learning objectives and a debriefing were also part of the exercise. Some ideas investigated include the disconnection between the actual party's characteristics and the revealed preferences of the students during the debriefing-a lesson of collective action-and the satisfaction and learning outcomes experienced by a minority of students as the result of being political activists and having their preferences realized in the makeup of their class party.

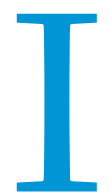
n February 2008, fourth grade students at Roberts Elementary School, a public school in the Houston Independent School District, Texas, participated in an exercise intended to mimic the creation of a public good through a democratic process. The exercise, called "Class Party," involved student use of a voting process to decide on a theme, music, and food for a class party. Approximately 91 students across four separate classes participated in creating and enjoying the class party. Pre- and post-exercise assessments and a debriefing were also part of the activity. The statistical results of the student assessments show that the students who participated in the class party demonstrated significantly more improvement than the students in the class without the party on one of the two items related to a learning objective of the class party. The statistical results also highlight differences across several responses related to topics covered during the debriefing between the group of students that answered the questions after participating in the debriefing and the group of students that answered the questions before participating in the debriefing. The qualitative assessment reveals

Douglas Schuler is an associate professor of business and public policy at Rice University's Jesse H. Jones Graduate School of Business. He received his Ph.D. from the University of Minnesota and his BS from the University of California at Berkeley. His research interests are corporate political activity and corporate social responsibility.

Matthew Chappell is a first-year student at the University of Idaho College of Law. He recently received an MA in English from Northern Arizona University. He worked as an elementary school teacher in the Houston Independent School District for several years. L. Scott Baggett received his Ph.D. in Statistics from Rice University in 2000 and was employed at the Jesse H. Jones Graduate School of Business from 20oo to 2010. He is now employed with the United States Forest Service as Supervisory Statistician at the Rocky Mountain Research Station in Fort Collins, CO. that the students overall were mostly to highly satisfied with the class party, students who participated the most were the most satisfied, and students learned important lessons about the effects of voting and nonvoting on the characteristics of a public good.

\section{BACKGROUND}

The state of Texas requires fourth graders to meet a social studies standard as mandated by section 113.6 of the Texas Essential Knowledge and Skills (TEKS) standards. Bullet 18, "Citizenship," of this section states that the student must understand the importance of voluntary individual participation in the democratic process. Among other items, the student is expected to (a) explain how individuals can participate voluntarily in civic affairs at state and local levels, and (b) explain the role of the individual in state and local elections. Traditionally, these standards are met through reading (e.g., in a textbook), lectures, class discussions, and homework. The class party exercise, as described in the following sections, is an experiential and novel way to address some of these standards. The explicit goals of the class party are to investigate: (1) whether experiential participation teaches students lessons about the individual costs of voting and the effects of such voting (and nonvoting) on the composition of the public good (a lesson in collective action); and (2) whether a debriefing, held after the class party, could teach additional lessons about voting and a citizen's relationship to elected public officials.

\section{THE PROCESS: THE CLASS PARTY}

The class party experience extended over one school week (Monday through Friday), with a debriefing on the following Monday (see figure 1). 
Figure 1

The Class Party Week

\begin{tabular}{|l|l|l|l|l||l|}
\hline Mon & Tue & Wed & Thu & Fri \\
\hline $\begin{array}{l}\text { Pretest } \\
\text { about } \\
\text { Government }\end{array}$ & $\begin{array}{l}\text { Theme } \\
\text { Vote } \\
\text { during } \\
\text { Recess }\end{array}$ & $\begin{array}{l}\text { Music } \\
\text { Vote } \\
\text { during } \\
\text { Recess }\end{array}$ & $\begin{array}{l}\text { Food } \\
\text { Vote } \\
\text { during } \\
\text { Recess }\end{array}$ & $\begin{array}{l}\text { Party } \\
\text { Held during Class }\end{array}$ & \\
$\begin{array}{l}\text { Party } \\
\text { Announced } \\
\text { in Class }\end{array}$ & & & & \\
Posttest \\
about \\
Government
\end{tabular}

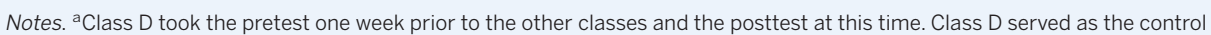
class for the party. ${ }^{\mathrm{b}} \mathrm{Classes} \mathrm{C}$ and $\mathrm{D}$ took the posttest before the debriefing. Classes $\mathrm{A}$ and $\mathrm{B}$ took the posttest after the debriefing.

FORMAL ASSESSMENT: PRE-

\section{AND POSTTEST ABOUT}

\section{GOVERNMENT}

We created an instrument called "Government Quiz" as a preand postexercise assessment of the class party. The quiz included 18 items: 10 general questions about government; 2 questions about voting related to the class party experience with a follow-up question about why students answered one of these they way that they did; and 5 questions about voting, political participation, and

On the first Monday, an assessment with a title unconnected to the class party ("Government Quiz") was given to the students in the morning. Later in the day, each teacher told his or her students that on Friday of that week, a class party would be held to celebrate all of the hard work that the kids had completed during the spring term. Furthermore, the teacher told the children that the class party would have a theme, music, and food chosen by the students themselves and would occur during a time of day normally accorded to academic subjects. In essence, the children were offered a public good in terms of a fun, in-class party.

To choose the theme, music, and food of the class party, the teacher suggested a student vote through an unspecified process (most participating students adopted an open "show of hands" vote). The caveats were that the voting was voluntary (students could participate if they chose) and would occur during the students' 30-minute recess period. On Tuesday, at the onset of the school day and right before recess, the classroom teacher announced that any student who wished to vote for the theme could go to their classroom during recess (escorted by a teacher) and participate in the voting. On Wednesday, the same process was applied to the vote on the music, and on Thursday, the same process was applied to the vote on the food. A teacher was present (although not necessarily the teacher of the student) to record the vote and the outcome. What this voluntary voting procedure during recess accomplished for each student was to create a private cost to political participation.

On Thursday evening, the teacher worked with several volunteer parents (sworn to secrecy) to organize the theme, music, and food for the party, based on the voting outcomes. One class created a movie/Oscars theme with rock music and pizza, popcorn, pretzels, and fruit. The second class created a Hawaiian beach theme with Hawaiian music and pizza. The third class created a beach-themed party with Jersey Boys music and barbeque. The fourth class created a Club Penguin-themed party with rock music and pizza. Each class had its party on Friday afternoon.

The following Monday, we conducted a 3o-minute debriefing in each classroom to talk about students' experiences with the party and relate it to themes about political participation and public policy. The debriefing would be classified as "development/ exploration," in which students were able to learn more about the perceptions of other students to gain a more complete picture of the simulation exercise beyond their personal experience (Peters and Vissers 2004, 77). elected officials related to the debriefing. The appendix summarizes the questions.

Four classes participated, classified as A, B, C, and D. For Classes $\mathrm{A}, \mathrm{B}$, and $\mathrm{C}$, we administered two quizzes. The first quiz was held on the Monday of the class party week before the teacher announced anything about the class party. The second quiz was given on the Monday morning following the class party. For Class $\mathrm{D}$, our control, we administered three quizzes. The first quiz was given on the Monday one week before the administration of the first quizzes for Classes A, B, and C and before any announcement of a class party. The second quiz was given on the Monday of the class party week but still before anything was announced about the party. The third quiz was given on the Monday morning following the class party. We gave Classes A and B the second quiz after the debriefing. We gave Class $\mathrm{C}$ the second quiz before the debriefing and gave Class $\mathrm{D}$ the third quiz before the debriefing. Therefore, the results of Classes A, B, and C between the first and second quizzes contain the "party effect," while the results of Class D between the first and second quiz contain the "no party effect." Classes A and B between the first and second quizzes additionally show the "debrief effect." Class $\mathrm{C}$ between the first and second quiz and Class D between the second and third quiz show the "no debrief effect." Figure 2 shows the placement of the classes into each condition. During the week, none of the teachers gave assignments or had in-class discussions related to items on the government quiz.

\section{RESULTS: PRE- AND POSTTEST ABOUT GOVERNMENT}

We were interested in whether students were able to improve their quiz scores as a result of the class party. We expected that Classes $\mathrm{A}, \mathrm{B}$, and $\mathrm{C}$ would demonstrate more improvement than Class D on the two items related to the party because of the party effect. Furthermore, we expected that Classes A and B would show greater improvement than Classes $\mathrm{C}$ and $\mathrm{D}$ on the five items related to political participation and elected officials that were part of the debriefing discussion.

The results of the statistical analysis on the government quiz provide some support for these expectations. To capture the party effect, we compared Class D to the other three classes, forming two groups. Within each group, we examined the frequency of the responses for the two questions related to the class party. Each of the two groups was partitioned into four categories: (1) those who responded correctly on both quizzes, (2) those who responded incorrectly on both quizzes, (3) those who responded correctly on 
Figure 2

Research Design

\begin{tabular}{|l|c|c|}
\hline \multicolumn{1}{|r|}{ Posttest after Debriefing } & Yes & No \\
\hline Class Party & & \\
\hline Yes & A, B & C \\
\hline No & - & D \\
\hline
\end{tabular}

the first quiz and incorrectly on the second quiz, and (4) those who responded incorrectly on the first quiz and correctly on the second quiz. Statistical analysis indicated a difference in the responses ( $p=.0510$, Fisher's Exact Test $\operatorname{Pr} \leq$ o.0695). Observing the responses to individual questions, the group with the parties had more students improve on Question 11 across their two quizzes (that is, move from an incorrect to a correct response) than expected. The class without a party (the control) had fewer students improve on Question 11. However, the results of the group with the parties were not statistically different from the results of the control group on Question 17.

To capture the debriefing effect, we compared Classes $\mathrm{C}$ and $\mathrm{D}$ to Classes A and B, again forming two groups (for Class D, we used the difference between the second and third quiz so that the party, but not the debriefing, was present in the analysis). Within each group, we examined the frequency of the responses on five questions that were addressed in the debriefing but not in the class party itself. Each of the two groups was partitioned into four categories similar to those used in the previous analysis of party effects. In three of the five questions, the debriefed classes (Classes $\mathrm{A}$ and B) differed significantly on their responses as measured by the $\chi^{2}$ probability test $(p<.10$, a fourth question was $p<.1022)$ from the two classes that did not have a debriefing. These results offer mixed support that the debriefing raised issues related to the learning objectives differently across the two groups.

We found an individual-level effect for the students who participated in the voting related to class party. For students answering Question 17 on the second quiz correctly ("Do you think that all laws reflect the desires of the majority of the people living in the country?" yes/no), their response was strongly and positively correlated $(p=.0195)$ with both the number of times that they voted (a maximum of three) and whether or not they voted. A correct response to Question 11 (about individual costs), however, was not significantly correlated with the number of times voted or whether or not students voted.

\section{SUBJECTIVE ASSESSMENT OF STUDENTS DURING THE DEBRIEFING AND BEYOND}

The debriefing aimed to create a purposeful discussion of the class party's relationship to voting and the composition of public goods, as well as the relationship between citizens and elected public officials (Lederman 1992). We tried to find fissures between what the party actually was and what the students had desired. In some of the classes, there was not much controversy: the party fairly accurately represented the desires of the students. However, in other classes, considerable disconnects emerged between the theme of the class party and what students had desired. For example, one of the classes chose a beach theme. During the debriefing, we entertained suggestions for alternative themes. Several themes were suggested and a video games theme was chosen by a show of hands. We asked some of the most vocal supporters of the video games idea if they had suggested and voted for this theme during the previous week. A bit shamefacedly, most said that they had not participated in the voting because they were enjoying their recess during the voting period. During the debriefing, students discovered two important lessons about voting: (1) the results of a vote do not necessarily reflect the preferences of the majority, and (2) one's own free-riding behavior can contribute directly to this outcome.

The students' general response was one of retrospection: those who participated in all three voting events seemed either thoroughly or somewhat pleased with the outcome of their voting activity. The students who seemed most satisfied with their efforts were those who not only participated in all three voting opportunities, but who also, after engaging in the vote, saw their preferences realized in the form of party music, food, and theme. Some students who participated fully in all voting rounds, however, seemed only somewhat satisfied with the effect of their participation on the composition of the class party. The disparity in satisfaction level appeared to lie in the fact that while some student voters got exactly what they voted for-theme, music, foodothers did not because of the majority rules structure of the individual voting rounds.

Further discussions occurred in the classrooms after the debriefing. These student discussions centered on the idea that voting does make a difference in the context of the democratic process, but that even active, deliberate participation does not necessarily guarantee that the outcome of the vote will fall in line with one's own preferences. Some student voters found themselves at odds with the class majority during voting rounds but were unable to do anything about it. This issue surfaced in several students' postdebriefing comments regarding their attitude toward future voting. Some students pointed out that they had needed to persuade and negotiate with others for their voting preferences to even be considered. These students assumed the role of political activists, presumably reaching the conclusion that while voting was a necessary component to getting what they wanted in a democratic event, it was not the only component.

\section{REFLECTIONS: WHAT WORKED?}

Many parts of the class party exercise were effective. First, the children had a fun experience, not only enjoying the fruits of their decisions, but also participating in making those decisions themselves. Many of the teachers corresponded with us during the week of the party to inform us of the students' excitement about the party and the various decisions that they had made during the week. As described previously, several students were proud to assume the role of political activists during the class party and to see how their civic participation resulted in public goods mirroring their personal interest. This experiential aspect of the class party exercise can reinforce topic material from lectures, readings, or other formal homework (Sugar 1998).

Second, in most of the classes, elements of the class party differed from the preferences the students revealed during the debriefings. In one class, sports and video game themes were significantly 
more popular than the beach theme that had been chosen in the previous week via the voting process. Although people familiar with collective action theory might not be surprised by such an outcome, many students were surprised by the concept that something as seemingly democratic as a voluntary vote can produce an outcome that is not the most favored by the majority. Thus, the class party succeeded in creating an experiential experience that mimicked collective action.

Third, the debriefing became another way to engage students and reinforce lessons about political participation and the consequences of low levels of participation (Lederman 1992). We were able to talk to the students about how elected officials receive information, why they respond to certain things and not others, how a constituent could put an issue on the agenda of his or her elected representative, and related topics. How information was produced through voting during the class party was an important element of this discussion. As a result, the discussion on these topics was more nuanced and personal than a typical discussion following a textbook reading on the subject.

\section{REFLECTIONS: WHAT DID NOT WORK?}

The connection between the assessment instrument, the government quiz, and the desired pedagogical outcomes was weaker than we had hoped. The two items in the government quiz were too far removed in their wording from the students' experiences in creating and participating in the class party. Although the debriefing was directed at closing this gap, for some students, the connection between the class party and the government quiz was not clearly made. We suggest that other researchers use more pretests of their assessment instrument than we did.

The research design did not allow us to disaggregate a party/ voting/debriefing effect from a teacher/classroom effect. The party and debriefing are nested within the teacher/classroom effect. There are two possible ways to address this. First, researchers could randomize students from all of the classes into each of the conditions, although this task might be logistically complicated across classes. Another option would be to make groups within classes. In this iteration of the exercise, an entire class would not participate in the same party, but rather, multiple class parties would occur in a single class and a student would attend his or her group's party. This approach might be more feasible logistically and might also make the impact of not voting or not seeing one's preferences realized more salient if individuals in the class were able to see others getting a party that they wanted. But in choosing this option, the individual groups are likely to be much smaller, which might minimize the free-rider effect (Olson 1965) that we saw when using the class as a whole.

\section{EXTENSIONS}

An extension to the direct voting system used in the class party exercise would be to use a representative system. Instead of using direct voting to decide each of the party's elements, as we did, students could run for office, representing different manifestations of the party's elements (i.e., one student could represent "Green Planet/U2/Tacos," another "Rodeo/Hannah Montana/ Pizza," and another "Under the Sea/Shakira/Ice Cream"). The purpose of this exercise would be to create the experience of costly individual voting along with the element of campaigning (with its effects on the costs and benefits of the public good), the ultimate election of the representative, and the realization of the newly formed public good.

If one teaches multiple classes (or multiple sections of a class), one might conduct the class party using both the representative and direct voting models. A joint debriefing might be held to compare and contrast the experiences of the different groups of students.

\section{NOTE}

We thank Guy Whitten for encouraging us to expand the experiential exercise and Scott Tonidandel for his useful comments on research design. We thank Linda Smith, principal of Roberts Elementary School, for allowing us to conduct this exercise at her school. We also thank Ashley Browning, Matthew Chappell, Telfia Johnson, and Jane Versavolic, the fourth grade teachers, for working with us and some of their parents to coordinate the class party. We especially thank the fourth grade students of Roberts Elementary School.

\section{REFERENCES}

Lederman, Linda C. 1992. "Debriefing: Toward a Systematic Assessment of Theory and Practice." Simulation \& Gaming 23: 145-6o.

Olson, Mancur. 1965. The Logic of Collective Action. Cambridge, MA: Harvard University Press.

Peters, Vincent A. M., and Geert A. N. Vissers. 2004. "A Simple Classification Model for Debriefing Simulation Games." Simulation \& Gaming 35: 70-84.

Sugar, Steve. 1998. Games that Teach: Experiential Activities for Reinforcing Training. San Francisco: Jossey-Bass. 


\section{APPENDIX: Government Quiz Questions}

\section{Questions Relating to Class Party}

11. The states do not charge you any money to vote-all eligible persons can register to vote for free. Can you think of any other costs to voting? (You might think about the costs to your mom or dad when they vote.)

17. Do you think that all laws reflect the desires of the majority of the people living in the country? yes/no

18. Why did you answer the way you did on question 17 ?

\section{Questions Relating to Debriefing}

9. In the 2004 election, what percentage of the citizens eligible to vote actually voted? (a) about $90 \%$; (b) about $65 \%$; (c) about $33 \%$; (d) about $10 \%$

12. Are fourth graders allowed to send an email to an elected official, like the president, a member of Congress, or the mayor of Houston?

13. A constituent of an elected official (such as a member of Congress) is someone who lives in a district or territory. Why do you think an elected official cares about his or her constituents?

14. Do you think that an elected official talks to most of his or her constituents during their term in office?

15. What is one way that an elected official might be able to find out what his or her constituents desire?

\section{Control Questions}

1. Who is the President of the United States?

2. Who is the Mayor of Houston?

3. Can you name any one of the candidates who is running for election for president of the United States in 2008 ?

4. What is the highest law in the United States? (a) The Declaration of Independence; $(b)$ the Supreme Law; (c) the Constitution; ( $d$ ) the Public Law

5. The First Amendment to the U.S. Constitution provides individuals living in the U.S. a number of rights. What is one of the rights that you have because of the First Amendment?

6. What is one thing that the U.S. federal (national) government does that affects your life?

7. What is one thing that the City of Houston does that affects your life?

8. In Texas, how old do you have to be to vote in an election? (a) 18 years; (b) 21 years; (c) 40 years; (d) every age can vote

10. Who do you think votes with a higher frequency? (a) senior citizens over 65 ; or (b) young people ages $18-24$

11. Have you ever spoken to, written a letter, or sent an e-mail to an elected official? yes/no 


\section{CAMBRIDGE}

\section{JOURNALS}
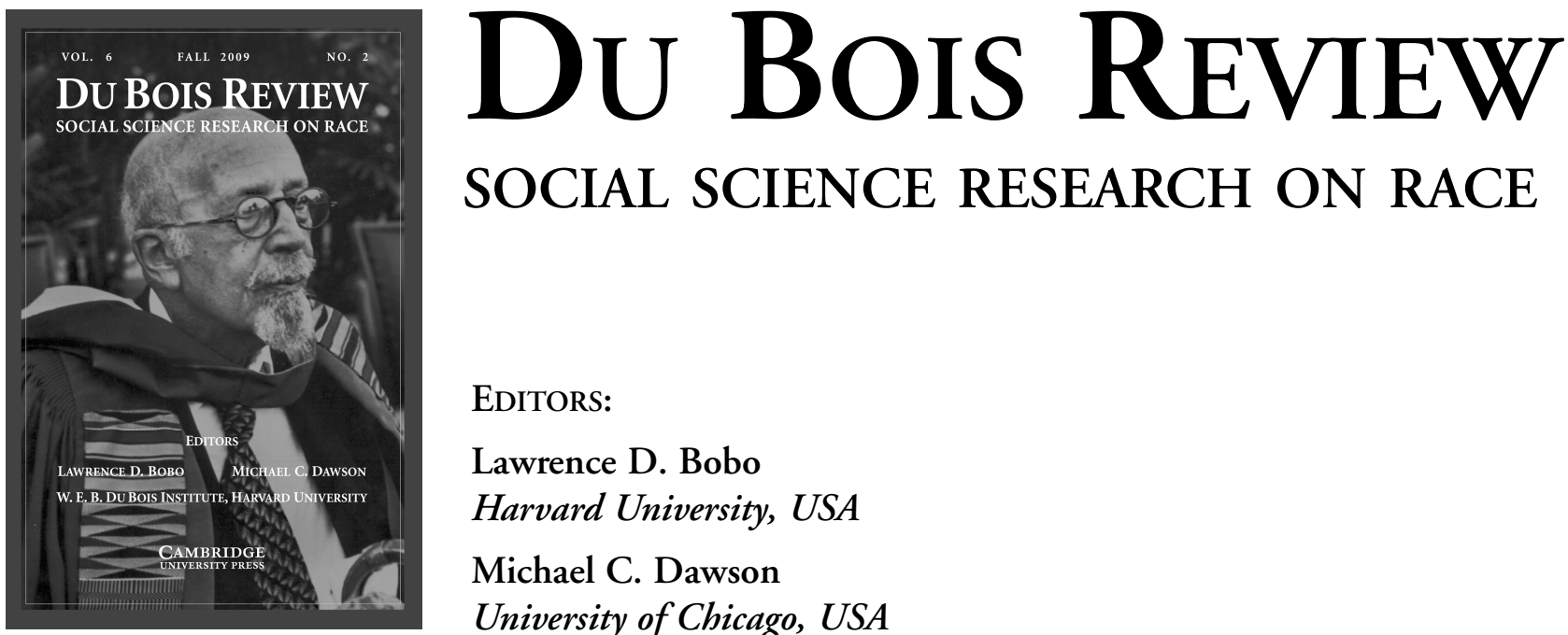

\section{EDITORS:}

Lawrence D. Bobo

Harvard University, USA

Michael C. Dawson

University of Chicago, USA

\section{W.E.B. Du Bois Institute for African and African American Research, Harvard University}

Du Bois Review: Social Science Research on Race $(D B R)$ is an innovative periodical that presents and analyzes the best cutting-edge research on race from the social sciences. It provides a forum for discussion and increased understanding of race and society from a range of disciplines, including but not limited to economics, political science, sociology, anthropology, law, communications, public policy, psychology, and history.

Each issue of $D B R$ opens with remarks from the editors concerning the three subsequent and substantive sections: STATE OF THE DisCIPLINE, where broad-gauge essays and provocative think-pieces appear; STATE OF THE ART, dedicated to observations and analyses of empirical research; and STATE OF THE DisCOURSE, featuring expansive book reviews, special feature essays, and occasionally debates.

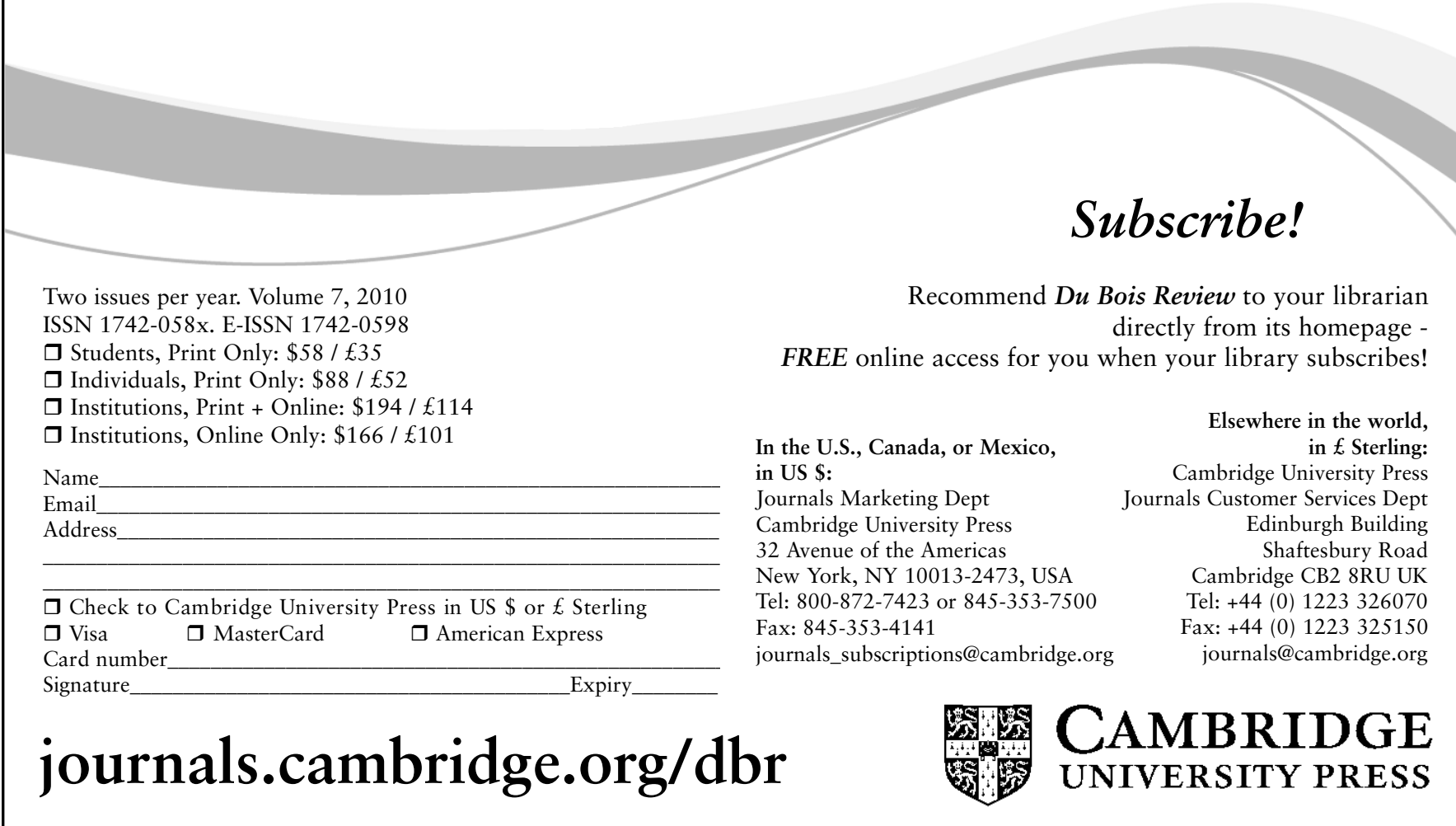

